\title{
Debt, Equity, and Information
}

\author{
Matthias M. M. Buehlmaier*
}

September 28, 2013

\begin{abstract}
Most firms issue financial assets such as debt or equity (e.g. bonds or stock) to outside investors. While these financial assets differ greatly in their characteristics, their diversity has received little attention in the literature. Filling this important gap in the literature, this paper views debt and equity as financial contracts and asks why they are optimal instead of other financial contracts. By endogenizing the bankruptcy process, this paper shows how debt and equity arise as a consequence of an optimal allocation of cash-flow rights and monitoring rights, and how equity leads to dividend signaling.
\end{abstract}

JEL classification: C78, D82, D86, G32, G33, G35.

Keywords: Financial contracting, security design, debt and equity, monitoring, information asymmetry, renegotiation and bargaining.

${ }^{*}$ Faculty of Business and Economics, The University of Hong Kong, Pokfulam Road, Hong Kong. Phone: +852 2219 4177, Fax: +852 2548 1152, email: buehl@hku.hk, web: www.buehlmaier.net. My greatest debt is to my committee members Klaus Ritzberger and Anne Villamil, who provided me with invaluable advice and comments about this paper. I would like to express my deeply felt gratitude to them as they have constantly and generously shared their knowledge with me. I would like to thank Alessandro Citanna (the Co-Editor) and two anonymous referees for their valuable comments and suggestions. I also would like to thank Filippo Balestrieri, Effi Benmelech, Eva CarcelesPoveda, Thomas Dangl, Sarah Draus, Zsuzsanna Fluck, Vito Gala, Christian Haefke, Christopher Hennessy, Philipp Illeditsch, Eren Inci, Stefan Krasa, Felix Meschke, Stijn Van Nieuwerburgh, Gordon Phillips, Pegaret Pichler, Ehud Ronn, Colin Rowat, Ariel Rubinstein, Jamsheed Shorish, Leopold Soegner, Alex Stomper, Marti Subrahmanyam, Xuan Tam, Sheridan Titman, Jörgen Weibull, Stefan Wendt, Wei Xiong, Haiping Zhang, Alexander Zimper, and the participants in the VGSF paper writing conference, the Microeconomics Jour Fixe at the Institute of Advanced Studies Vienna, the AFFI 2008 Annual Meeting, Econometric Society's NASM 2008, FEMES 2008, EEA-ESEM 2008, the 2008 Annual Meeting of the Southern Economic Association, the 12th Conference of the Swiss Society for Financial Market Research (SGF), and the 10th SAET Conference for valuable discussions and comments. I acknowledge financial and research support received at the Vienna Graduate School of Finance (VGSF), where preliminary versions of this paper were written. VGSF is financially supported by the Austrian Science Fund (FWF). 


\section{Introduction}

There is a large literature that considers deals between financiers and those who need financing, for example deals between outside investors and small startup companies. A central question in this literature is to ask why certain financial assets such as debt and outside equity are optimal, and why we do not observe financial assets with fundamentally different characteristics. While the security design literature has made great strides in explaining a large number of stylized facts, its key challenge is that it often views debt and equity as results of changes in model assumptions as opposed to changes in model parameters. ${ }^{1}$ In the sense that a model is an abstraction of the real world, the security design literature shows that in one world, all firms issue only debt, while in another world all firms issue only equity. Clearly, these results are not a fully satisfactory description of reality, and it is of great economic import to bring both worlds together.

This paper bridges both worlds by rationalizing a substantial number of stylized facts about debt and equity using a single parsimonious model. This parsimony is a significant contribution to the literature because it allows one to investigate novel interactions between economic forces that would otherwise be hard to explore. In doing so, this paper combines two strands of the security design literature. On the one hand, there are papers that focus on the assignment of control rights, but where contracts are incomplete (see Aghion and Bolton (1992)). On the other hand, there are papers that rely on informational frictions to derive the optimal structure of contracts (see Townsend (1979)). Combining these two strands of the literature, this paper generates

\footnotetext{
${ }^{1}$ Notable exceptions that endogenize some or all security characteristics of both debt and equity include Dewatripont and Tirole (1994), Berglöf and von Thadden (1994), Fluck (1998), Fulghieri and Lukin (2001), Biais et al. (2007) and DeMarzo and Fishman (2007).
} 
both debt and equity contracts without having to assume incompleteness for the set of contracts. In particular, this paper shows how the interaction of cash flow rights and monitoring rights results in optimal allocations giving rise to debt and equity contracts. Furthermore, it shows how equity contracts lead to endogenous dividend signaling. Finally, the paper provides novel implications for bankruptcy, making a case for reorganization (e.g. out-of-court private negotiation or Chapter 11 bankruptcy) instead of liquidation (e.g. Chapter 7 bankruptcy).

A major difference between this paper and most of the previous literature is the way bankruptcy is conceptualized. The previous literature often assumes perfect ex post enforcement of contracts through an exogenous unmodeled authority. ${ }^{2}$ While this assumption has served as an important building block for laying out the foundations of security design, it is not a fully satisfactory descriptive tool. This paper thus relaxes this assumption and, building on Krasa and Villamil (2000), makes bankruptcy endogenous along two dimensions. First, the investor may file with a court for bankruptcy protection and seize assets by enforcing a transfer payment. Second, the transfer payment itself is endogenous and is part of the contract. This approach to modeling bankruptcy is important because it endogenizes cash flow rights. Furthermore, it shows a novel way to alleviate managerial moral hazard by incentivizing the entrepreneur to signal private information through monetary payouts, thus furthering our understanding of optimal payout policy and dividend signaling.

The economic intuition driving this paper's results follows from considering two extreme cases for illustration: a small startup company, e.g. a high-tech startup in Silicon

\footnotetext{
${ }^{2}$ Prior research interprets bankruptcy as a bad signal about the state of nature and the resulting transfer of control (see Aghion and Bolton (1992)), a low payout (see Diamond (1984)), the act of verification (see Townsend (1979) and Gale and Hellwig (1985)), or the intervention of outside investors in management (see Dewatripont and Tirole (1994)).
} 
Valley such as Google in 1999, and a mature company, e.g. an automaker in Detroit such as General Motors. The startup (e.g. Google) has risky cash flows because it is uncertain whether it survives. If it survives, however, it can become highly profitable. This profitability, together with the fact that there is asymmetric information between an outside investor and the entrepreneur who runs the company, means that there is also a large profit to hide. To deal with this problem, the outside investor can audit (i.e. monitor) the firm at a cost. Since this cost is still low for the small startup, the optimal contract has monitoring rights, especially since there may be a large profit to hide. To capitalize on this large profit, the investor also requires state-contingent cash flow rights. These state-contingent cash flow rights coupled with monitoring rights are consistent with equity contracts that are used for venture capital financing of startups like Google. ${ }^{3}$ In contrast, the monitoring of the mature company (e.g. General Motors) is very costly because the company is large and old. Furthermore, the company's cash flows are stable with a low growth potential. These low-risk cash flows coupled with high monitoring costs make monitoring unattractive. The investor thus relinquishes her monitoring rights and is content with state-independent cash flow rights, yielding debt as the optimal contract.

The rest of this paper is organized as follows. Section 2 introduces the model. The key results are summarized in Section 3 by showing the relation to debt and equity and deriving empirical predictions. The model is formally solved in Section 4, while Section 5 provides a model extension to many states of nature. Finally, Section 6 concludes. For easier cross-referencing, results throughout this paper are summarized

\footnotetext{
${ }^{3}$ There are also small firms whose outside funding mainly consists of bank loans, i.e. debt. An example for this type of firm is an entrepreneur running a restaurant. These firms, however, often do not have a high growth potential or do not have very risky cash flows. They are thus unlikely to receive venture capital (i.e. equity) financing. This is consistent with this paper as long as the relatively low growth potential or the relatively stable cash flows dominate the cost-efficient information policy.
} 
in the form of lemmata and propositions, culminating in the paper's main theorem. The proof of the main theorem is contained in the Appendix.

Related Literature. In a closely related paper, Krasa and Villamil (2000) show that debt and equity contracts arise as a consequence of an economic friction that determines whether the original contract can be renegotiated. The key difference is that this paper considers renegotiation in the spirit of Rubinstein bargaining, while Krasa and Villamil consider a repeat-contract approach.

In the same spirit as this study, Dewatripont and Tirole (1994) examine why debt and equity differ fundamentally. Dewatripont and Tirole have several outside investors, which allows for the simultaneous issuance of debt and equity (one investor is the residual claimant on cash flows rights). In contrast, there is only one outside investor in this study, which precludes the simultaneous issuance of debt and equity.

This paper also relates to the bankruptcy procedure literature, since some of its results can be interpreted as reorganization (e.g. out-of-court private negotiation or Chapter 11 bankruptcy) versus liquidation (e.g. Chapter 7 bankruptcy). There exists an extensive law and economics literature that is primarily concerned with finding optimal bankruptcy procedures (see Roe (1983), Baird (1986), Bebchuk (1988), Aghion et al. (1994), and Berkovitch and Israel (1999)). Similar in spirit, part of the financial contracting literature studies the effects of bankruptcy procedures on managers' incentives (see Aghion and Bolton (1992), Bolton and Scharfstein (1996), and Berkovitch et al. (1998)) and the protection of creditors' claims (see Cornelli and Felli (1997)). 
Figure 1: Timeline

\begin{tabular}{llllll} 
& & & & & \\
\\
\hline investor & entrepr. & investment & entrepr. & investor & investor \\
proposes & accepts & project & disburses & does/does not & ends the game/ \\
contract & rejects & realizes $x$ & cash $v$ & monitor & $\begin{array}{l}\text { enforces/ } \\
\text { renegotiates }\end{array}$
\end{tabular}

\section{The Model}

This section describes the model, whose timeline is summarized by Figure 1. Consider two risk neutral agents, an investor with deep pockets ("she") and a penniless entrepreneur ("he"). The entrepreneur has an investment opportunity and needs outside financing. To finance the project, the investor proposes a contract that the entrepreneur can accept or reject. ${ }^{4}$ If the entrepreneur rejects the financing, the project becomes worthless. Ex ante, both agents share a common prior $\beta:=P\left(X=x_{H}\right) \in(0,1)$ about the project's random cash flow $X \in\left\{x_{L}, x_{H}\right\}$, where $x_{L}<x_{H}$. The common prior $\beta$ represents agents' belief about the extent to which the entrepreneur has a profit to hide. An alternative interpretation of $\beta$ is agents' beliefs about the growth potential of the company. After the contract is signed, nature makes a draw and determines the project's cash flow realization $x \in\left\{x_{L}, x_{H}\right\}$. As a result, an informational asymmetry arises: the entrepreneur observes the project's cash flow, but the investor does not. In this ex post sense, I refer to an entrepreneur with the low cash flow realization $x_{L}$ as of low type, while an entrepreneur with $x_{H}$ is of high type.

After the cash flow realization, the entrepreneur has the opportunity to pay out parts of this cash flow to the investor. This payout could correspond to dividends in equity contracts, or to coupon payments in debt contracts. This payout, denoted by $v \geq 0$, is

\footnotetext{
${ }^{4}$ This approach is in the spirit of Bolton and Scharfstein (1990) and Kaplan and Strömberg (2003).
} 
voluntary, and it represents money on the table that cannot be withdrawn subsequently. Note that $v$ may be zero or strictly positive, and that there is no inherent restriction on $v$ that prevents the entrepreneur from overpaying or underpaying. Furthermore, it is important to keep in mind that $v$ is not an announcement, but an actual payout. As such, the voluntary payout has the dual role of transferring wealth and acting as a potential signaling device. After receiving the payout $v$, the investor updates her belief about the project according to Bayes' rule to $\beta_{v}:=P\left(X=x_{H} \mid V=v\right)$. She conditions on the event $\{V=v\}$, where the conditional distribution of the random variable $V \mid X=$ $x_{E}$ represents the entrepreneur's endogenous payout strategy for $E \in\{L, H\}$.

The contract may or may not carry monitoring rights. If it does, the investor, after receiving $v$, has the opportunity to monitor (i.e. observe) the entrepreneur's project at a monitoring cost $c$. Monitoring is a binary decision (yes/no) of the investor and this decision is observable by the entrepreneur. After her monitoring decision the investor chooses between one of the following actions: (i) she ends the game, (ii) she initiates bankruptcy proceedings and takes the entrepreneur to court ("enforcement"), or (iii) she renegotiates the original contract. The first case accounts for the possibility that the investor is content with the payout she received. The second and third cases account for the possibility that the payout is too low, leaving the investor unsatisfied.

Enforcement resolves potentially asymmetric information: the court identifies the project's cash flow realization, transfers the enforceable payment from the entrepreneur to the investor, and ends the game. Enforcement is costly for both agents. If the investor decides to take the entrepreneur to court, each agent incurs bankruptcy costs $b>0$ that represent legal fees and expenses. The model assumes that $c<2 b$, which means that the total bankruptcy costs $2 b$ are larger than the monitoring costs $c$. The motivation for this assumption is that during enforcement, the court does the equivalent 
of monitoring (i.e. finding out the true cash flow realization) and furthermore enforces a transfer payment.

The possibility of enforcement is independent of whether the contract carries monitoring rights. Even an investor who does not have monitoring rights can initiate bankruptcy proceedings. Such an investor resolves asymmetric information by using the court as a monitor. In this sense, the monitoring rights stipulated by the contract refer to monitoring outside of bankruptcy. The key differences between monitoring and enforcement are as follows: (i) monitoring does not necessarily end the game, but enforcement does, and (ii) monitoring does not entail a transfer payment, but enforcement does. The first difference implies that the investor can use the information obtained by monitoring to optimize over subsequent choices. On the other hand, if the investor enforces, she forgoes this opportunity because enforcement ends the game.

Renegotiation, as illustrated by Figure 2, is similar in spirit to Rubinstein bargaining (see Rubinstein (1982) and Rubinstein (1985)). The key differences are that (i) only the investor makes requests and (ii) enforcement is possible in each round. Renegotiation consists of an infinite number of rounds where later rounds are being discounted since time is valuable. Time costs ensure that agents prefer early agreements by depriving them of incentives to play waiting games. In each renegotiation round, the investor makes a request for a payout. The entrepreneur then accepts or rejects this request. If he accepts, he makes the requested payout and the game ends. If he rejects, the investor updates her belief about the cash flow realization according to Bayes' rule. Using her posterior belief, the investor decides whether to enforce or to continue. Enforcement proceeds as described in the previous paragraph and the game ends after enforcement. If the investor continues, she initiates a subsequent round of renegotiation that is structurally identical to the previous round. 
Figure 2: One Round of Renegotiation
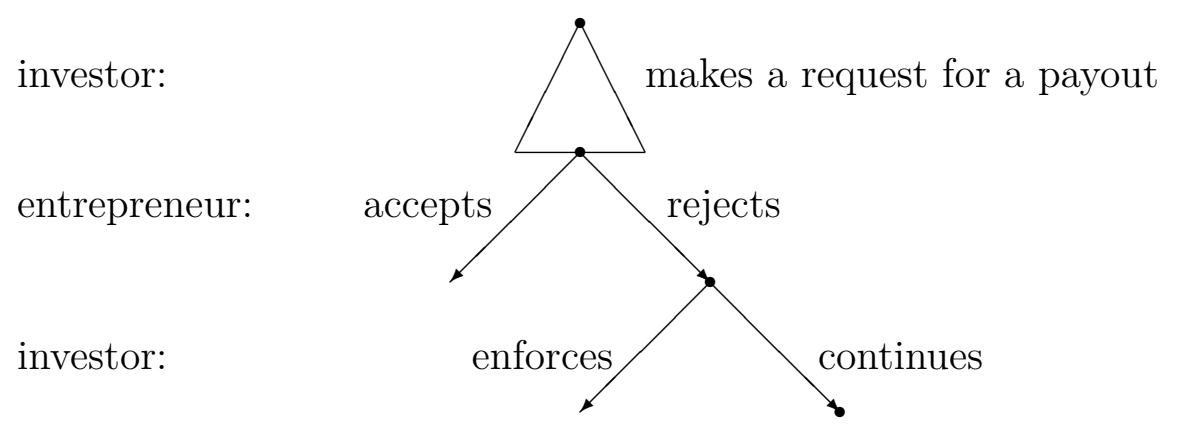

This model lets the investor make the requests instead of the entrepreneur, implying that the investor has the bargaining initiative. The reason for this modeling choice is that the bargaining process should capture central elements of real-world Chapter 11 bankruptcy, where indeed the investor has the bargaining initiative (see Section 3 for more details). While there might be theoretical interest in letting the entrepreneur propose requests, this is not further pursued here because it is not a fully satisfactory description of the economic problem addressed in this paper.

The contract consists of two parts. The first part determines whether or not the contract carries monitoring rights. The second part is the enforceable payment $f$, where $f:\left\{x_{L}, x_{H}\right\} \rightarrow \mathbb{R}_{+}$. To interpret $f$, ignore for a moment the entrepreneur's budget constraint. The number $f(x)$ denotes the payment that the investor obtains through enforcement, given that the cash flow realization is $x$. If the investor is informed, she knows that she can obtain $f(x)$ from enforcement. If she is uninformed, she expects to obtain $(1-\beta) f\left(x_{L}\right)+\beta f\left(x_{H}\right)$, since she does not know the cash flow realization. As in Krasa and Villamil (2000), it is important to note that $f$ is not set by the court, but by the contracting parties. As such, agents do not anticipate the enforceable payment set by the court, but instead set it themselves.

The ex ante budget constraint of the entrepreneur is $x-b \geq 0$. Limited liability 
of the entrepreneur ensures that the court cannot put the entrepreneur into debt. As a consequence, the limited liability constraint $f(x) \leq x-b$ obtains. After making the payout $v$, there is also the ex post budget constraint of the entrepreneur, given by $x-b-v \geq 0$. This is the maximum amount available for the court to seize, without putting the entrepreneur into debt. Limited liability implies that the ex post enforceable payment $F$ is the minimum of the enforceable payment and the ex post budget constraint, that is, $F(x, v):=\min \{f(x), x-b-v\}$. For notational convenience, let us define $F_{L}:=F\left(x_{L}, v\right)$ and $F_{H}:=F\left(x_{H}, v\right)$ for the remainder of this paper. The enforceable payment $F$ is a simplified version from Krasa and Villamil (2000), where $F$ may always depend on the voluntary payout $v$. In contrast, $F$ in this paper only depends on the voluntary payout if $x-b-v<f(x)$ holds; in that case, we have $F(x, v)=$ $x-b-v$, meaning that every dollar paid out reduces the enforceable payment by one dollar. This simplifying assumption ensures that the optimization problems of the entrepreneur and the investor during the potentially infinite renegotiation stage under potentially asymmetric information are well behaved, so that an analytical solution can be derived recursively.

Given the notation introduced in the previous paragraphs, Table 1 summarizes agents' payoffs. When interpreting this table, it is important to keep in mind that consumption takes place only after the game ends. Furthermore, time preferences of agents during renegotiation are modeled using the discount factor $\delta \in(0,1)$.

\section{Preview of Key Results}

This section provides a preview of this paper's key results. Since discounting is assumed to be sufficiently small throughout the paper, the following corollary restates the main 
Table 1: Investor's and Entrepreneur's Payoffs

This table summarizes the payoffs of the investor and the entrepreneur. Consumption takes place only after the game ends. Row (1) obtains if the investor ends the game immediately after her monitoring decision. This implies that the investor does not enforce and that the investor does not enter into renegotiation. Row (2) obtains from immediate enforcement, that is, enforcement before renegotiation takes place. Row (3) obtains if agents enter renegotiation and the entrepreneur accepts a request for a payout of size $r$ in round $k$, where $\delta \in(0,1)$ represents agents' time preferences (time is valuable). Row (4) obtains if the investor enforces in round $k$.

\begin{tabular}{lcc}
\hline & Investor & Entrepreneur \\
\hline (1) No enforcement, no renegotiation & $v$ & $x-v$ \\
(2) Immediate enforcement & $v+F(x, v)-b$ & $x-v-F(x, v)-b$ \\
(3) Renegotiation w/o enforcement & $\delta^{k}(v+r)$ & $\delta^{k}(x-v-r)$ \\
(4) Renegotiation with enforcement & $\delta^{k}(v+F(x, v)-b)$ & $\delta^{k}(x-v-F(x, v)-b)$ \\
\hline
\end{tabular}

theorem from Section 4.4 for the limiting case $\delta \rightarrow 1$.

Corollary. As discounting vanishes, that is, as $\delta \rightarrow 1$, the following results obtain. For any parameter values, agents end up negotiating their way around enforcement. If $\beta<c /\left(x_{H}-x_{L}\right)$, the optimal contract is state-independent since $f\left(x_{L}\right)=f\left(x_{H}\right)$, and the contract does not carry monitoring rights outside of bankruptcy. In this case, the entrepreneur conceals information by pooling his payout $v$ at zero. If $c /\left(x_{H}-x_{L}\right) \leq \beta$, the optimal contract is state-contingent since $f\left(x_{H}\right) \geq f\left(x_{L}\right)+c / \beta$, and the contract carries monitoring rights. In this case, the entrepreneur reveals the state of the project's cash flow by signaling this private information with the voluntary payout $v$.

Figure 3 illustrates how the optimal contract relates to debt and equity. As the figure shows, two major cases obtain: $\beta<c /\left(x_{H}-x_{L}\right)$, corresponding to debt, and $\beta>c /\left(x_{H}-x_{L}\right)$, corresponding to equity. There is also the borderline case of $\beta=$ $c /\left(x_{H}-x_{L}\right)$ in which agents may play a mixed strategy over debt and equity. With some caution, this case might be interpreted as a simple form of capital structure, 
Figure 3: Debt and Equity

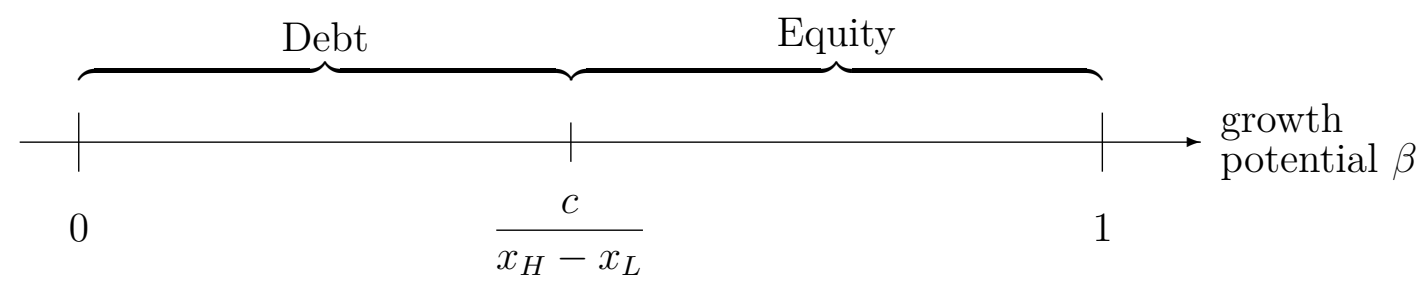

i.e. a combination of debt and equity. For a true capital structure to emerge, a second outside investor would be needed as a residual claimant (see Dewatripont and Tirole (1994)). The following discussion thus puts aside this borderline case and focuses on the pure-debt and pure-equity cases that are typical for a single investor.

To discuss the debt-like contract, suppose that $\beta<c /\left(x_{H}-x_{L}\right)$, which means that the monitoring costs are large, the stakes are small, and agents are relatively certain that the investment project's growth potential is small. By "small stakes" I mean that the potential cash flow realizations $x_{L}$ and $x_{H}$ are relatively close together. When these conditions are satisfied, the corollary states that the contract does not carry monitoring rights outside of bankruptcy. Furthermore, the contract induces cash flow rights that are state-independent. Payout policy is nonexistent in the sense that the entrepreneur makes no voluntary payout and does not reveal information to the investor. As a consequence, the optimal contract is debt-like.

Alternatively, it is possible to argue that one could always assign monitoring rights to the debt-like contract, since monitoring rights in this model can be assigned at no cost. One could interpret this contract as a degenerate equity contract, where "degenerate" means that cash flow rights are state-independent instead of state-contingent. However, if an arbitrarily small cost of assigning monitoring rights is introduced into the model, this result breaks down and, consistent with reality, debt contracts no longer confer monitoring rights outside of bankruptcy. This is so because agents know from the 
outset that, with debt, it is too costly to exercise these monitoring rights. That is, monitoring will not take place, even if it is allowed by the contract. The costs of assigning monitoring rights can be justified by increased legal fees, since lawyers need to be paid, e.g. to work out the details of what monitoring means and the conditions describing when this right can be exercised. ${ }^{5}$ It is important to keep in mind that these costs do not have to be large. In fact, arbitrarily small costs are sufficient for the degenerate equity contract to be replaced by debt.

In this debt-like contract, it is important to note that the statement $f\left(x_{L}\right)=f\left(x_{H}\right)$ does not automatically imply that the outside investor's cash flow rights are always state-independent. Whether bankruptcy occurs still does have an effect on cash flow rights, like it has in real-life defaultable debt. This is so because bankruptcy entails deadweight costs, so the outside investor's payoff is different in bankruptcy.

To discuss the equity-like contract, suppose that $\beta>c /\left(x_{H}-x_{L}\right)$, meaning that the monitoring costs are small, the stakes are large, and agents are relatively certain that the growth potential of the project is high. In this case, the corollary states that the contract carries unconditional monitoring rights and induces cash flow rights that are state-contingent. Furthermore, endogenous dividend signaling obtains. As a consequence, the optimal contract is equity-like. The optimal contract, in particular, is preferred equity, which has seniority over common stock. Seniority means in this case that in the event of a bankruptcy, holders of preferred stock receive money before common stockholders do. This is consistent with the above contract since the investor still may receive a payout in bankruptcy. Furthermore, holders of preferred stock receive dividends before common stockholders receive any payouts. Dividends are, however,

\footnotetext{
${ }^{5}$ The literature on incomplete contracts is based on a related assumption, namely that writing complete contracts is prohibitively costly. A complete contract specifies all rights and duties for every possible future state of the world.
} 
not guaranteed even with preferred stock, which means that dividend signaling is still possible.

It is important to note that, although endogenous dividend signaling is a key result of this paper, dividends are not necessary for the remaining results to hold. Even if the voluntary payout $v$ is omitted from the model, all remaining results about cash flow rights and monitoring rights stay qualitatively the same.

This paper also makes a case for renegotiation instead of liquidation of a company, e.g. out-of-court private negotiation or Chapter 11 bankruptcy instead of Chapter 7 bankruptcy under the United States' Bankruptcy Code. ${ }^{6}$ Chapter 7 bankruptcy directly corresponds to enforcement in this paper, meaning that the company is liquidated. In contrast, out-of-court private negotiation or Chapter 11 bankruptcy means that the company is reorganized. For Chapter 11 bankruptcy, most of the action happens out of court, although investors formally file with a court for protection. Chapter 11 bankruptcy usually means that investors take control of business operations, subject to the oversight and jurisdiction of the court. The goal of Chapter 11 bankruptcy as well as out-of-court private negotiation is not liquidation, but the reorganization of the company to avoid the deadweight costs associated with liquidation and to increase ex post efficiency. The same idea applies to the equilibrium in this paper, where agents renegotiate their way around enforcement (i.e. around Chapter 7 bankruptcy) to avoid enforcement costs and to increase ex post efficiency.

\footnotetext{
${ }^{6}$ For a description of the economics of bankruptcy procedures used around the world, see Aghion et al. (1994).
} 


\section{Optimal Contract and Endogenous Payout Policy}

This section solves the model. The equilibrium concept is that of a perfect Bayesian equilibrium with subgame perfection. The analysis proceeds backwards.

\subsection{Informed Investor}

Consider an informed investor in the last stage of the game (see Figure 1). Being informed means that the investor knows the cash flow realization $x$, which can be brought about by monitoring, or by signaling on the part of the entrepreneur. Given this information structure, the following lemma characterizes the entrepreneur's decision to accept or reject requests for payouts during renegotiation.

Lemma 1. In equilibrium, the entrepreneur accepts a request with probability one if he is indifferent between accepting and subsequent enforcement.

Figure 4 illustrates the intuition behind Lemma 1 by showing the investor's expected utility as a function of the payout request made by the investor. The jump in the figure occurs because of enforcement and bankruptcy costs. For an equilibrium to exist, the figure needs to have a well-defined maximum. This maximum only exists if the entrepreneur accepts with probability 1.

Proposition 1 (Informed Investor). Assume that discounting is sufficiently moderate. ${ }^{7}$ At the last stage of the game, the informed investor enters renegotiation, makes the request $F(x, v)+b$ in the first round, and the entrepreneur accepts. The investor's utility is $\delta(v+F(x, v)+b)$, and, with subscript $i$ denoting that the investor is informed, the entrepreneur's utility is given by $\pi_{i}^{E}:=\delta(x-v-F(x, v)-b)$.

\footnotetext{
${ }^{7}$ This statement means that $\delta$ exceeds a given constant in the unit interval. This constant does not contribute to the economic intuition and is not stated explicitly. It can be derived from the corresponding proofs.
} 
Figure 4: On the left-hand side, the entrepreneur accepts the request $F(x, v)+b$ with probability 1 . On the right-hand side, the entrepreneur rejects the request $F(x, v)+b$ with strictly positive probability.
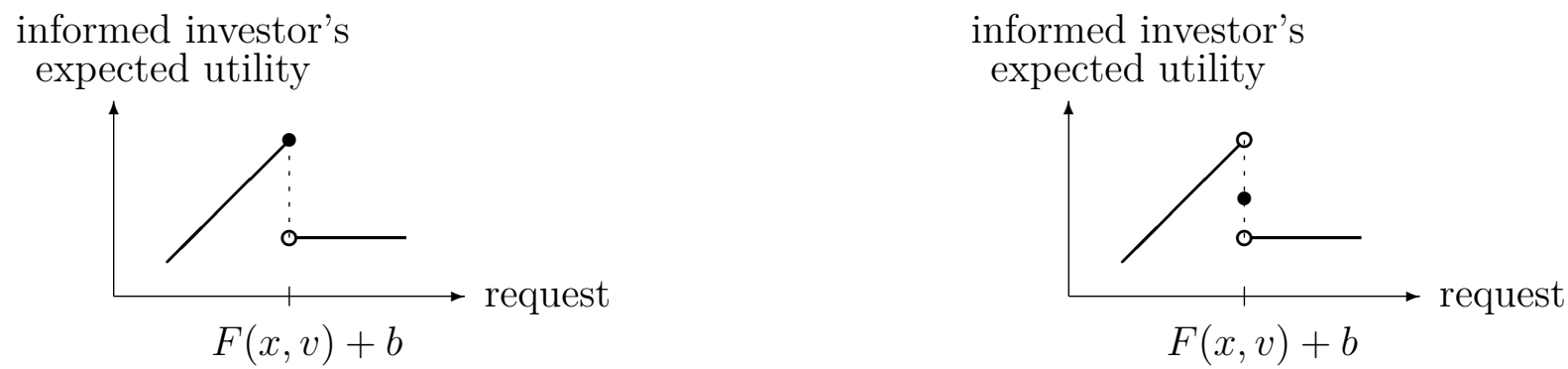

The case of the informed investor illustrates two key features of the model. First, agents renegotiate their way around enforcement because enforcement entails deadweight costs. Second, the investor has a first-mover advantage by anticipating the entrepreneur's reaction and thus exploiting it. As a result, the investor avoids paying her own bankruptcy costs and furthermore coaxes the entrepreneur towards transferring his bankruptcy cost to her. I refer to this effect as the double benefit of renegotiation.

\subsection{Uninformed Investor at the Last Stage of the Game}

Instead of an informed investor, we now consider an uninformed investor $\left(\beta_{v} \in(0,1)\right)$ at the last stage of the game (see Figure 1). To make the derivation of the results more intuitive, I introduce an auxiliary constraint on the set of admissible contracts. The purpose of this constraint is to eliminate a few unimportant corner cases. It also is possible to derive this paper's results without this auxiliary constraint, but it would complicate the presentation, while not yielding deeper economic insights. This constrained is termed the proportionality constraint, and it states that the court may not seize more from the poor than it seizes from the rich, i.e. $f\left(x_{L}\right) \leq f\left(x_{H}\right)$.

There are two potential equilibria during renegotiation under asymmetric informa- 
tion. First, the investor renegotiates according to a worst-case scenario, ensuring that every type has incentives to accept in the first round. This request is $F_{L}+b$, and it is obtained by making the low type indifferent between accepting and enforcement. I refer to this case as take-it-or-leave-it $(t)$. Second, the investor screens the entrepreneur by extending renegotiation to two rounds. In the first round, she makes a request $r_{1}$ such that the high type accepts and the low type rejects. In the second round she makes a request $r_{2}=F_{L}+b$ such that the low type accepts. I refer to this case as elicitation tactics $(e)$, which can be rationalized from a hypothetical last stage of the game by the investor's belief that the entrepreneur will reject all subsequent requests. Satisfying a no-mimicking constraint and using the proportionality constraint, it can be shown that $r_{1}=\delta r_{2}+(1-\delta)\left(x_{H}-v\right)>r_{2}$.

If the investor is fairly certain that she faces a high type, she might be tempted to make a request larger than $r_{1}$, forcing the high type to accept by threatening enforcement. The problem with this approach is that enforcement after such a high request is not credible. The dilemma is that, after a rejection of such a request, the investor becomes informed: she knows that she is facing a low type because a high type would have accepted. However, now that she knows $x=x_{L}$, she no longer has any incentive to enforce. Instead, tailoring a specific request to the low type gives her a higher utility because of the double benefit of renegotiation (see Proposition 1). She thus deviates and does not enforce, making a request larger than $r_{1}$ infeasible. This result is summarized as follows.

Lemma 2. In equilibrium, the uninformed investor cannot make a request larger than $r_{1}$ and force a high type to accept by threatening enforcement otherwise.

The two equilibrium properties of renegotiation from Section 4.1 also apply to this 
section: agents never enforce during renegotiation because of deadweight costs; furthermore, the investor exploits the double benefit of renegotiation. As a result, the investor never ends the game immediately after her monitoring decision because it is dominated by renegotiation. These results are summarized by the following proposition.

Proposition 2 (Uninformed Investor Part 1). Assume that discounting is sufficiently moderate. At the last stage of the game, the uninformed investor renegotiates through take-it-or-leave-it or elicitation tactics, or she enforces immediately. (The investor never ends the game immediately after her monitoring decision.) Her expected utilities from playing take-it-or-leave-it and elicitation tactics are $\pi_{t}^{I}:=\delta\left(v+F_{L}+b\right)$ and $\pi_{e}^{I}:=\delta^{2}\left(v+F_{L}+b\right)+\delta(1-\delta) \beta_{v} x_{H}$, respectively. The entrepreneur's utilities are $\pi_{t}^{E}:=\delta\left(x_{E}-v-F_{L}-b\right)$ and $\pi_{e}^{E}:=\delta^{2}\left(x_{E}-v-F_{L}-b\right)$ for all $E \in\{L, H\}$.

\subsection{Uninformed Investor at the Second to Last Stage}

Consider the uninformed investor at the second to last stage of the game (see Figure 1), and assume for now that the contract carries monitoring rights. If the investor monitors $(m)$, she is subsequently informed, and by Proposition 1 her expected utility is $\pi_{m}^{I}:=\delta\left[v+\left(1-\beta_{v}\right) F_{L}+\beta_{v} F_{H}+b-c\right]$. Since monitoring makes the investor informed, the entrepreneur's utility is $\pi_{m}^{E}:=\pi_{i}^{E}$.

For the uninformed investor, monitoring strictly dominates immediate enforcement in expectation, since the total bankruptcy costs are larger than the monitoring costs (formally, $c<2 b$, as discussed in Section 2). Propositions 1 and 2 then imply that the investor always enters renegotiation. The following proposition summarizes.

Proposition 3 (Uninformed Investor Part 2). Assume that discounting is sufficiently moderate. Consider the uninformed investor (i.e. $\left.\beta_{v} \in(0,1)\right)$ at the second to last stage 
of the game. In this case, the investor plays either take-it-or-leave-it, elicitation tactics, or she monitors and plays according to Proposition 1.

\subsection{Deriving the Optimal Contract}

The following steps derive the optimal contract and the entrepreneur's payout policy. A central element in the following analysis is the investor's posterior belief $\beta_{v} \in[0,1]$ about the entrepreneur's type. This posterior belief determines the action taken by the investor, which in turn determines the entrepreneur's utility. The entrepreneur's utility is thus a function of the investor's posterior in equilibrium. However, the entrepreneur may change the investor's posterior by choosing a appropriate payout strategy for his voluntary payout $v$. So by appropriately choosing a payout strategy, the entrepreneur may be able to influence whether his utility function is going to be $\pi_{i}^{E}, \pi_{t}^{E}, \pi_{e}^{E}$, or $\pi_{m}^{E}$.

In the following steps, we thus think of $\pi_{i}^{E}, \pi_{t}^{E}, \pi_{e}^{E}$, and $\pi_{m}^{E}$ as functions of the voluntary payout $v$. Also suppose for the time being that the contract carries monitoring rights.

\section{Step 1: The Low Type's Limited Liability Constraint Is Binding}

Proposition 4 (Limited Liability). Assume that discounting is sufficiently moderate. Then the low type's limited liability constraint is binding in equilibrium, i.e. $f\left(x_{L}\right)=$ $x_{L}-b$.

Because of this result, the remainder of the paper fixes the enforceable payment of the low type at $f\left(x_{L}\right)=x_{L}-b$. The economic intuition follows directly from Figure 5 . If the low type's limited liability constraint is not binding and thus $f\left(x_{L}\right)<x_{L}-b$, the entrepreneur refuses any payout (i.e. $v=0$ ). The investor thus has nothing to lose by increasing $f\left(x_{L}\right)$ until limited liability binds. Note that the same type of argument 
Figure 5: Low and High Types' Utilities When $f(x)<x-b$

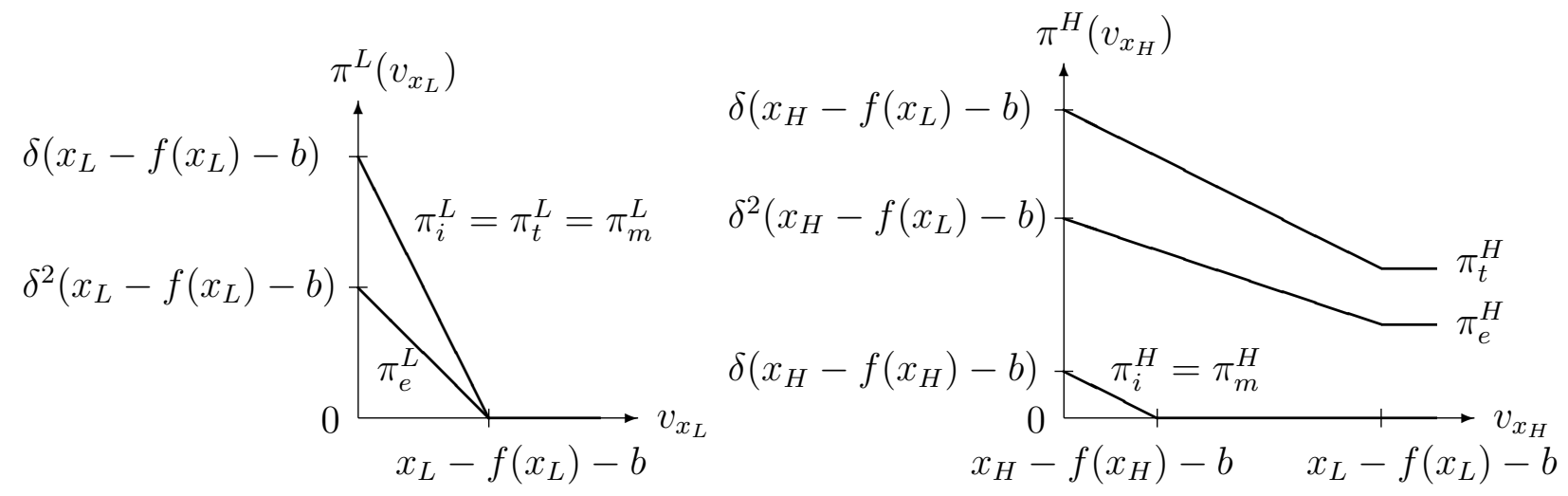

does not go through in analogy for the enforceable payment $f\left(x_{H}\right)$ of the high type. When considering $f\left(x_{H}\right)$, there are cases in which the entrepreneur has incentives to signal his type, which prevents the argument from going through unchanged.

\section{Step 2: Posterior Beliefs and the Investor's Best Response}

The investor's best response after observing the payout $v$ critically depends on her posterior $\beta_{v}$. Since this posterior is a number in the unit interval $(0,1)$, it is useful to partition the unit interval into subintervals that make it easy to characterize the investor's best response. These subintervals are given by

$$
\Theta_{t}:=\left(0, \min \left\{\theta_{1}, \theta_{2}\right\}\right], \quad \Theta_{e}:=\left[\theta_{1}, \theta_{3}\right], \quad \Theta_{m}:=\left[\max \left\{\theta_{2}, \theta_{3}\right\}, 1\right)
$$

where we only consider the part of the $\Theta_{j}$ that overlaps with the interval $(0,1)$ and where $\theta_{1}:=\frac{x_{L}}{x_{H}}, \theta_{2}:=\frac{c}{f\left(x_{H}\right)-f\left(x_{L}\right)}, \theta_{3}:=\frac{c-(1-\delta) x_{L}}{f\left(x_{H}\right)-f\left(x_{L}\right)-(1-\delta) x_{H}}$. Depending on the game's parameters, the partition of the unit interval consists of two or three intervals. Figure 6 illustrates the case with three intervals. The interpretation of these intervals is about the optimism of the investor pertaining to the investment project's cash flow realization. 
Figure 6: The Intervals $\Theta_{t}, \Theta_{e}$, and $\Theta_{m}$ Partition the Unit Interval

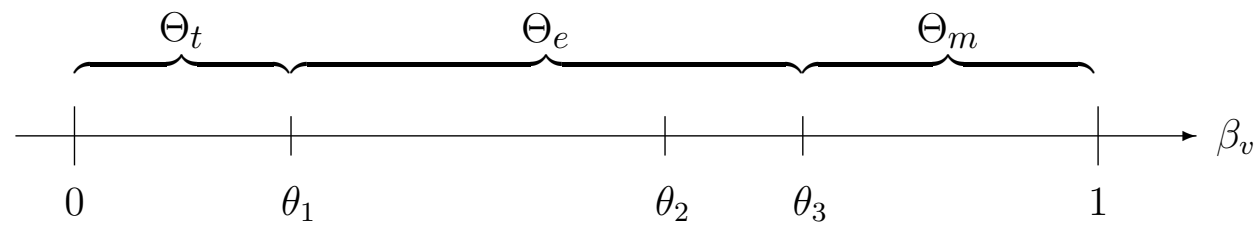

If $\beta_{v} \in \Theta_{t}$, for example, the investor is relatively certain that a low cash flow realization occurred. On the other hand, $\beta_{v} \in \Theta_{m}$ means that the investor is confident that there was a high cash flow realization.

Proposition 5 (Posterior Beliefs Matter). Assume that discounting is sufficiently moderate. Consider the uninformed investor at the second to last stage of the game. If $f\left(x_{L}\right)=f\left(x_{H}\right)$, the investor never plays $m$ and decides between playing $t$ and $e$ by $\pi_{t}^{I} \leq \pi_{e}^{I} \Leftrightarrow \beta_{v} \in\left[\theta_{1}, 1\right)$. If $f\left(x_{L}\right)<f\left(x_{H}\right)$ and $\beta_{v} \in \Theta_{j}$, then it is optimal for the investor to play $j$.

Similar to Rubinstein (1985), Proposition 5 specifies a clear connection between the investor's belief and the equilibrium. If $\beta_{v} \in \Theta_{t}$ and the investor is thus relatively certain to be facing a low type, the investor plays take-it-or-leave-it. This is so because time is valuable and the investor does not want to lose time speculating on the unlikely event of facing a high type. If on the other hand $\beta_{v} \in \Theta_{e}$ and the investor is thus more certain to be facing a high type, the investor plays elicitation tactics. This strategy is optimal, since the investor is now willing to take the gamble by trying to screen the entrepreneur. Finally, if $\beta_{v} \in \Theta_{m}$ and the investor is thus even more certain that the entrepreneur is the high type, she is willing to spend the monitoring costs to become informed. Monitoring is optimal because the investor knows that her bargaining power is much higher in a perfect information game than in a game of incomplete information. 


\section{Step 3: Prior Beliefs and the Entrepreneur's Best Response}

Knowing the investor's response to a given posterior belief from Proposition 5, the entrepreneur can decide on his optimal payout policy.

Proposition 6 (Prior Beliefs Matter). Assume that discounting is sufficiently moderate. Suppose that $f\left(x_{H}\right)=f\left(x_{L}\right)$. If $\beta<\theta_{1}$, the entrepreneur pools his payout at zero. If $\beta \geq \theta_{1}$, the entrepreneur signals his type.

Suppose that $f\left(x_{H}\right)>f\left(x_{L}\right)$. If $\beta \in\left(\Theta_{t} \cup \Theta_{e}\right)^{o}$, the entrepreneur pools his payout at zero. If $\beta \in \Theta_{m}$, the entrepreneur plays a potentially degenerate mixed strategy between signaling and payout pooling at zero.

The key driving force behind this result is that with $f\left(x_{L}\right)=x_{L}-b$ at its limited liability constraint (see Proposition 4), the low type's utility is always zero, no matter whether payout pooling or signaling via $v$ occurs. So for payout pooling or signaling, only the incentives of the high type matter. And the high type's incentives are to mislead the investor as far as possible, as will be discussed next.

There are two cases to consider. First, suppose that the investor has a belief $\beta$ that is relatively close to zero, meaning that the investor thinks she likely faces a low type. If, against the investor's conjecture, nature has in fact drawn a high type, the high type does not want to reveal that he is hiding a high cash flow realization. He therefore pools his payout with the low type. Second, suppose that the investor has a belief $\beta$ that is relatively close to 1 , meaning that the investor thinks she likely faces a high type. This believe makes it optimal for the investor to monitor, should the entrepreneur not signal his type. As a consequence, the entrepreneur is indifferent between pooling and signaling, since in both cases the investor will end up being informed and will proceed according to Proposition 1. 


\section{Step 4: Optimal Contract and Payout Policy}

Given the entrepreneur's optimal payout policy from the previous step, the investor is now able to figure out the optimal contract. As in the previous step, there are two cases to consider. The first case is about the investor having a prior belief $\beta$ that is relatively close to zero, so the investor believes to likely face a low type. In this case, the investor knows that she is going to play either take-it-or-leave-it or elicitation tactics, and for both of these strategies the investor cannot commit to making a request that depends on $f\left(x_{H}\right)$, as shown by Lemma 2. This is why it is optimal for her to choose a value $f\left(x_{H}\right)$ that is equal or close to $f\left(x_{L}\right)$, since $f\left(x_{H}\right)$ is irrelevant for the investor's payoff. The investor also knows that any monitoring threat is not credible, and thus she does not need to assign monitoring rights to the optimal contract.

The second case is that of a prior belief $\beta$ being relatively close to 1 , meaning that the investor believes that she is likely to face a high type. Given this belief, the investor knows that she will monitor and become informed. Since the payoff of the informed investor does depend on $f\left(x_{H}\right)$, she wants to choose $f\left(x_{H}\right)$ as large as possible. This gives rise to a state-contingent contract with attached monitoring rights. The entrepreneur, however, offers a tradeoff to the investor. If the investor chooses a slightly lower $f\left(x_{H}\right)$, the entrepreneur is willing to signal his type and thus save the monitoring costs for the investor. This offer is possible since the entrepreneur can credibly commit to signaling by Proposition 6 .

The following theorem formalizes and refines the argument above. The refinement lies in comparing monitoring with take-it-or-leave-it (when $\beta<\theta_{1}$ ), and comparing monitoring with elicitation tactics (when $\theta_{1} \leq \beta$ ). Both cases are similar in the sense that the former is the limit of the latter when discounting vanishes, i.e. when $\delta \rightarrow 1$. Figure 7 illustrates the enforceable payment of the high type as a function of the 
Figure 7: Optimal Enforceable Payment for the High Type when $\delta \rightarrow 1$

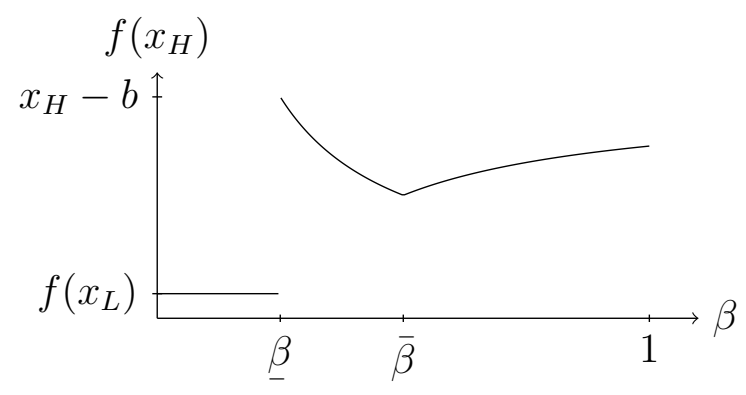

prior belief in the limiting case, illustrating that the contract is state-independent on the left-hand-side (i.e. $f\left(x_{H}\right)=f\left(x_{L}\right)$ ) and state-contingent on the right-hand-side (i.e. $\left.f\left(x_{H}\right) \neq f\left(x_{L}\right)\right)$. For the following theorem, the definitions of new cutoff values for the prior belief $\beta$ are necessary.

$\underline{\beta}:=\frac{c}{x_{H}-x_{L}}, \bar{\beta}:=\frac{2 c}{x_{H}-x_{L}}, \underline{\beta}^{\prime}:=\frac{c-(1-\delta) x_{L}}{x_{H}-x_{L}-(1-\delta) x_{H}}, \bar{\beta}^{\prime}:=\frac{2 c-(1-\delta) x_{L}}{x_{H}-x_{L}-(1-\delta) x_{H}}$.

Observe that $\lim _{\delta \rightarrow 1} \underline{\beta}^{\prime}=\underline{\beta}$ and $\lim _{\delta \rightarrow 1} \bar{\beta}^{\prime}=\bar{\beta}$ imply that the theorem's second part collapses to its first part. If discounting vanishes (i.e. $\delta \rightarrow 1$ ), the theorem yields the corollary from Section 3.

Theorem (Optimal Contract and Payout Policy). Assume that discounting is sufficiently moderate. By Proposition 4, $f\left(x_{L}\right)=x_{L}-b$.

Suppose that $\beta<\theta_{1}$. Then:

$$
f\left(x_{H}\right)= \begin{cases}f\left(x_{L}\right) & \text { if } \beta \in(0, \beta) \\ f\left(x_{L}\right)+c / \beta & \text { if } \beta \in[\bar{\beta}, \bar{\beta}] \\ x_{H}-b-c / \beta & \text { if } \beta \in(\bar{\beta}, 1)\end{cases}
$$

The payout policy and monitoring rights are related as follows. If $\beta<\underline{\beta}$, the contract does not carry monitoring rights, and the entrepreneur pools his payout. If $\underline{\beta} \leq \beta$, the 
contract carries monitoring rights, and the entrepreneur signals his type.

Suppose that $\theta_{1} \leq \beta$. Then payout policy and monitoring rights relate in the same way as above with $\underline{\beta}$ replaced by $\underline{\beta}_{-}^{\prime}$, and $f\left(x_{H}\right)$ given by

$$
f\left(x_{H}\right)= \begin{cases}f\left(x_{L}\right)+2(1-\delta)\left(x_{H}-x_{L}\right) & \text { if } \beta \in\left(0, \beta^{\prime}\right) \\ f\left(x_{L}\right)+c / \beta+(1-\delta)\left(x_{H}-x_{L} / \beta\right) & \text { if } \beta \in\left[\beta^{\prime}, \bar{\beta}^{\prime}\right] \\ x_{H}-b-c / \beta & \text { if } \beta \in\left(\bar{\beta}^{\prime}, 1\right)\end{cases}
$$

\section{$5 \quad$ Extending the State Space}

In the previous sections, the entire analysis assumes that there are only two realizations of the state of nature $x \in\left\{x_{L}, x_{H}\right\}$. This section extends the state space so that the investment project's cash flow realization is drawn from an uncountable set. In addition

to checking the robustness of the results from the previous model, it is possible to distinguish debt and equity contracts from other financial contracts, e.g. call options, depending on whether the payments are concave, affine, or convex.

The cash flow realization $x$ is drawn from the continuous uniform distribution, i.e. the random variable $X$ follows $X \sim \mathcal{U}[0,1]$. To keep this variant of the model parsimonious and to focus on its essential elements, bankruptcy costs are assumed away and renegotiation is limited to one round. The remaining ingredients of the model stay unchanged.

Consider the case where the investor has monitored and is thus informed. Here as well as in the remainder of this section, the entrepreneur has no incentives to make a voluntary payout, so $v=0$. (This is in line with the discussion in Section 3, where the voluntary payment is also not necessary to derive the remaining results about cash flow rights and monitoring rights.) Standing at the last stage of the game, the investor always enforces whenever $f(x)>0$. The entrepreneur, knowing the investor's 
enforcement decision, refuses any request $r>f(x)$ and accepts any request $r<f(x)$. In turn, the investor chooses her request $r$ in a way that makes the entrepreneur indifferent between accepting and refusing. This request is given by $r=f(x)$. In equilibrium, the entrepreneur accepts this request (compare Lemma 1). Given this optimal request, the investor can figure out the optimal contract $f$, which pins down the entrepreneur to his reservation utility of zero. This optimal contract is given by $f(x)=x$, which is typical for an all-equity financed firm. Next, we discuss the complementary case of an uninformed investor.

Consider the case where the investor has not monitored and is thus uninformed. In the last stage of the game, the investor enforces whenever $E[f(X)]>0$. The entrepreneur, who knows the cash flow realization $x$, refuses if $r>f(x)$ and accepts if $r<f(x)$. Similarly to the case of the informed investor, the uninformed investor pins down the entrepreneur to his reservation utility when deciding on the optimal contract. The difference is that this pinning down now happens in expectation. Furthermore, the investor can jointly determine the optimal contract $f$ and the optimal request $r$, since the information available to the investor does not change over the first part of the game. As the following paragraph shows, there are multiple combinations of $f$ and $r$ that are optimal.

When deriving the optimal contract $f$ together with the optimal request $r$, the investor maximizes her expected utility. Since there are no deadweight costs, any increase in the investor's expected utility is accomplished by a decrease in the entrepreneur's expected utility. (Both expected utilities always sum up to $E[X]=1 / 2$.) As a consequence, any combination of $f$ and $r$ that makes the entrepreneur's expected utility equal to his reservation utility of zero maximizes the investor's expected utility. One such combination is $f(x)=\min \{x, 0.7\}$ and $r=0.56$, since it sets the entrepreneur's ex- 
pected utility to zero, i.e. $(E[X]-E[f(X)]) P(r>f(X))+(E[X]-r) P(r \leq f(X))=0$. The optimal contract $f(x)=\min \{x, 0.7\}$ is typical for an all-debt financed firm. Having established the optimal contracts for the informed and uninformed investor, we still need to consider when it is optimal for the investor to become informed.

When choosing the optimal contract at the outset of the game, the investor needs to consider whether it will be optimal for her to become informed later in the game by making use of her monitoring technology. In the same way as in Section 3, monitoring costs are a key determinant for this decision. If the monitoring costs are low, the investor knows at the outset that it will be optimal for her to monitor. She thus assigns monitoring rights to the contract, and chooses the equity contract $f(x)=x$. On the other hand, if the monitoring costs are high, the optimal contract does not contain monitoring rights, and the investor chooses the debt contract $f(x)=\max \{x, 0.7\}$. The qualitative conclusions obtained in previous sections about debt and equity in terms of cash flow rights and monitoring rights thus continue to hold in the case of more than two states of nature.

\section{Conclusion}

This paper contributes to the literature by investigating the diversity of financial assets, which has so far received little attention in the literature. It answers why debt and equity have optimal characteristics and furthermore sheds light on the economic circumstances in which debt or equity are optimal. While the prior literature has considered models that explain some of these results in separation, the results in this paper combine various strands of the literature and unify them in a parsimonious model. The distinguishing feature of this model is that, building on Krasa and Villamil (2000), 
bankruptcy is endogenized. Using endogenous bankruptcy, the results in this paper consistently describe the financing of small fast-growing startups through equity and the financing of large and mature companies through debt. Furthermore, it provides novel policy implications for bankruptcy, making the case for reorganization (e.g. out-of-court private negotiation or Chapter 11 bankruptcy) instead of liquidation (e.g. Chapter 7 bankruptcy).

\section{Appendix}

Proof of the Main Theorem. This proof discusses the case $\beta<\theta_{1}$; the case $\beta \geq \theta_{1}$ follows from a related line of argument. Let $\Pi_{m}^{I}\left(\zeta, f\left(x_{H}\right)\right)$ denote the investor's ex ante expected utility when $\beta \in \Theta_{m}$ and when the entrepreneur plays $\left(v_{L}, v_{H}\right)=(\varepsilon, 0)$ with probability $\zeta$ and $\left(v_{L}, v_{H}\right)=(0,0)$ with probability $1-\zeta$, for some $\varepsilon>0$. The case $\beta<\theta_{1}$ implies that the uninformed investor never plays $e$, and instead decides between playing $t$ and $m$ (see Propositions 5 and 6), i.e. $\beta \in \Theta_{t}$ or $\beta \in \Theta_{m}$. With $\lambda:=f\left(x_{L}\right)+c / \beta$ and $M:=\left[\lambda, x_{H}-b\right]$, it then holds that $\left(\beta \in \Theta_{m} \Leftrightarrow f\left(x_{H}\right) \in M\right)$, since $\theta_{2} \leq \beta$ is equivalent to $\lambda \leq f\left(x_{H}\right)$. The definition of $M$ implies that $M=\emptyset \Leftrightarrow \beta<\underline{\beta}$. If $f\left(x_{H}\right)=f\left(x_{L}\right)$, then by Propositions 5 and 6 the entrepreneur pools his payout at zero, and the investor plays $t$ and obtains $\pi_{t}^{I}=\delta x_{L}$.

Suppose that the game's parameters are such that $\beta<\beta$. That is, $M=\emptyset$, and there exists no $f\left(x_{H}\right) \in\left[f\left(x_{L}\right), x_{H}-b\right]$ such that $\beta \in \Theta_{m}$. Independent of the value of $f\left(x_{H}\right)$, the entrepreneur pools at zero and the investor plays $t$. Since $f\left(x_{L}\right)=x_{L}-b$, it follows that $\pi_{t}^{I}=\delta x_{L}$ for all $f\left(x_{H}\right)$. As a consequence, it is optimal for the investor to set $f\left(x_{H}\right)=f\left(x_{L}\right)$.

Suppose that the game's parameters are such that $\beta>\beta$. That is, $\lambda<x_{H}-b$, and the interval $M$ has positive length. By playing $f\left(x_{H}\right) \in M$, the investor can obtain at least $\Pi_{m}^{I}\left(0, x_{H}-b\right)=\delta\left[(1-\beta) x_{L}+\beta x_{H}-c\right]$, since $\Pi_{m}^{I}$ is increasing in $f\left(x_{H}\right)$, and since the entrepreneur's maximal punishment consists of playing $\zeta=0$. Since $\beta>\underline{\beta}$ implies that 
$c<\beta\left(x_{H}-x_{L}\right)$, it holds that $\Pi_{m}^{I}\left(0, x_{H}-b\right)>\delta x_{L}=\pi_{t}^{I}$. As a consequence, it is always optimal for the investor to play $f\left(x_{H}\right) \in M$. Knowing that the investor plays $f\left(x_{H}\right) \in M$, the entrepreneur plays a trigger strategy in the following sense. If the investor chooses a large value of $f\left(x_{H}\right)$, the entrepreneur plays maximal punishment by setting $\zeta=0$. If the investor chooses a low value of $f\left(x_{H}\right)$, the entrepreneur rewards the investor by signaling with probability 1 . That is, the entrepreneur plays the trigger strategy $\zeta_{l}\left(f\left(x_{H}\right)\right):=\mathbb{1}\left(f\left(x_{H}\right) \leq l\right)$, where $l$ denotes the threshold level and $\mathbb{1}$ denotes the indicator function. The entrepreneur chooses the threshold level $l$ as small as possible such that it is still optimal for the investor to play $f\left(x_{H}\right)=l$. That is, the entrepreneur chooses the smallest threshold level $l \in M$ such that $\Pi_{m}^{I}\left(0, x_{H}-b\right) \leq \Pi_{m}^{I}(1, l)$ still holds.

Suppose that $\Pi_{m}^{I}\left(0, x_{H}-b\right) \leq \Pi_{m}^{I}(1, \lambda)$, that is, $\beta \leq \bar{\beta}$. In this case it is optimal for the entrepreneur to play $l=\lambda$. In equilibrium, the investor plays $f\left(x_{H}\right)=\lambda$, and the entrepreneur signals with probability 1 . Although the investor does not monitor in equilibrium, she still assigns monitoring rights to the contract. Suppose that $\Pi_{m}^{I}(1, \lambda)<\Pi_{m}^{I}\left(0, x_{H}-b\right)$, that is, $\bar{\beta}<\beta$. In this case it is optimal for the entrepreneur to play $l>\lambda$ such that $\Pi_{m}^{I}(1, l)=$ $\Pi_{m}^{I}\left(0, x_{H}-b\right)$. Such an $l$ exists and is given by $l=x_{H}-b-c / \beta$. In equilibrium, the investor plays $f\left(x_{H}\right)=x_{H}-b-c / \beta$, the entrepreneur signals with probability 1 , and the investor also assigns monitoring rights to the contract.

\section{References}

Aghion, P. and Bolton, P. (1992). An incomplete contracts approach to financial contracting. The Review of Economic Studies, 59(3):473-494.

Aghion, P., Hart, O., and Moore, J. (1994). Improving bankruptcy procedure. Washington University Law Quarterly, 72:849.

Baird, D. G. (1986). The uneasy case for corporate reorganizations. The Journal of Legal Studies, 15(1):127-147.

Bebchuk, L. A. (1988). A new approach to corporate reorganizations. Harvard Law Review, 101(4):775-804. 
Berglöf, E. and von Thadden, E. (1994). Short-term versus long-term interests: Capital structure with multiple investors. Quarterly Journal of Economics, 109(4):1055-1084.

Berkovitch, E. and Israel, R. (1999). Optimal bankruptcy laws across different economic systems. The Review of Financial Studies, 12(2):347-377.

Berkovitch, E., Israel, R., and Zender, J. F. (1998). The design of bankruptcy law: A case for management bias in bankruptcy reorganizations. The Journal of Financial and Quantitative Analysis, 33(4):441-464.

Biais, B., Mariotti, T., Plantin, G., and Rochet, J.-C. (2007). Dynamic security design: Convergence to continuous time and asset pricing implications. Review of Economic Studies, 74(2):345-390.

Bolton, P. and Scharfstein, D. (1990). A theory of predation based on agency problems in financial contracting. American Economic Review, 80(1):93-106.

Bolton, P. and Scharfstein, D. S. (1996). Optimal debt structure and the number of creditors. Journal of Political Economy, 104(1):1-25.

Cornelli, F. and Felli, L. (1997). Ex-ante efficiency of bankruptcy procedures. European Economic Review, 41(3-5):475-485.

DeMarzo, P. and Fishman, M. (2007). Optimal long-term financial contracting. Review of Financial Studies, 20(6):2079-2128.

Dewatripont, M. and Tirole, J. (1994). A theory of debt and equity: Diversity of securities and manager-shareholder congruence. Quarterly Journal of Economics, 109(4):1027-1054.

Diamond, D. (1984). Financial intermediation and delegated monitoring. Review of Economic Studies, 51(3):393-414.

Fluck, Z. (1998). Optimal financial contracting: Debt versus outside equity. Review of Financial Studies, 11(2):383-418.

Fulghieri, P. and Lukin, D. (2001). Information production, dilution costs, and optimal security design. Journal of Financial Economics, 61(1):3-42.

Gale, D. and Hellwig, M. (1985). Incentive-compatible debt contracts: The one-period problem. Review of Economic Studies, 52(4):647-663.

Kaplan, S. and Strömberg, P. (2003). Financial contracting meets the real world: An empirical analysis of venture capital contracts. Review of Economic Studies, 70(2):281-315.

Krasa, S. and Villamil, A. P. (2000). Optimal contracts when enforcement is a decision variable. Econometrica, 68(1):119-134.

Roe, M. J. (1983). Bankruptcy and debt: A new model for corporate reorganization. Columbia Law Review, 83:527.

Rubinstein, A. (1982). Perfect equilibrium in a bargaining model. Econometrica, 50(2):97-109. 
Rubinstein, A. (1985). A bargaining model with incomplete information about time preferences. Econometrica, 53(5):1151-1172.

Townsend, R. (1979). Optimal contracts and competitive markets with costly state verification. Journal of Economic Theory, 21(2):265-293. 